\title{
Isolation of Keratosulfate-like Mucopolysaccharide Containing a Large Amount of Sialic Acid from Whale Cartilage Proteinpolysaccharide
}

\author{
Hiroki NaKagawa* \\ (Received September 5, 1970)
}

\begin{abstract}
It was undertaken to clarify some properties of sialic acid-containing mucopolysaccharide (SP) occurring as a component of whale cartilage proteinpolysaccharide (PP). After enzymatic degradation of PP with hyaluronidase and Pronase, the products were chromatographed on Sephadex columns, and the behavior of SP on the columns was examined. Moreover, SP was fractionated into five fractions by Dowex $1-\times 2$ chromatography, and these were analyzed for sialic acid, hexosamine, hexose, uronic acid, and sulfate. Consequently, it was clarified that SP was keratosulfate-like mucopolysaccharide containing a large amount of sialic acid as well as small amounts of galactosamine, mannose, and fucose.
\end{abstract}

Previous studies $^{1 /}$ have indicated that sialic acid in whale cartilage was a component of its proteinpolysaccharide (PP). This suggested that sialic acid-containing poly- or oligosaccharide occurred as a component of PP. The present studies were undertaken to clarify some properties of sialic acid-containing mucopolysaccharide liberated from PP by enzymatic degradation.

\section{Experimental}

Material. Cartilage pieces were prepared from a nasal septum of a sei whale, $B a$ laenoptera boraelis, as described previously. ${ }^{11}$

Preparation of PP from cartilage pieces. PP was extracted from cartilage pieces by the procedure described previously ${ }^{1)}$. It contained about $8 \%$ collagen. In order to remove the collagen, a solution of $3 \mathrm{~g}$ of $\mathrm{PP}$ in 1 liter of $0.05 \mathrm{M}$ sodium acetate buffer, $\mathrm{pH} 5.0$, was passed through a column $(3.5 \times 40 \mathrm{~cm})$ of $\mathrm{CM}$-cellulose equilibrated with the same buffer. To the effluent was added 2 volumes of ethanol, and then sodium acetate was added to a concentration of $1 \%$. The precipitate formed was collected by centrifugation, washed three times with $80 \%$ ethanol, then with absolute ethanol and ether, and dried in vacuo. This PP had a hydroxyproline content of about $0.1 \%$, showing that it was almost free from collagen. A solution of $100 \mathrm{mg}$ of the collagen-free PP in $20 \mathrm{ml}$ of $0.5 \mathrm{M} \mathrm{NaCl}$ was applied to a column $(5 \times 78 \mathrm{~cm})$ of Sephadex G-200 equilibrated with $0.5 \mathrm{M} \mathrm{NaCl}$, and eluted with the same salt solution (Fig. 1). PP was recovered from the fraction indicated by arrows in Fig. 1 by the addition of ethanol and sodium acetate as described above, redissolved in water, dialyzed, and freeze-dried. The analytical

* Lab. of Fish. Tech., Fac. of Agr., Kyushu Univ., Fukuoka, Japan. （中川浩毅：九州大学農学部 水産彆造学教室) 
values of the purified PP were as follows: sialic acid $2.93 \%$, hexosamine $21.3 \%$, uronic acid $15.8 \%$, hexose $7.14 \%$, protein $24.0 \%$.

Preparation of bovine testicular hyaluronidase. Fresh bovine testes were decapsulated, chopped, and dehydrated with acetone. Twenty grams of the acetone-dried material was extracted with $200 \mathrm{ml}$ of $0.1 \mathrm{~N}$ acetic acid by continuous stirring for $3 \mathrm{hr}$ at $4^{\circ} \mathrm{C}$. The extract was centrifuged at $4^{\circ} \mathrm{C}$, and the supernatant was adjusted to $30 \%$ of saturation with solid ammonium sulfate. After centrifugation, the supernatant was adjusted to

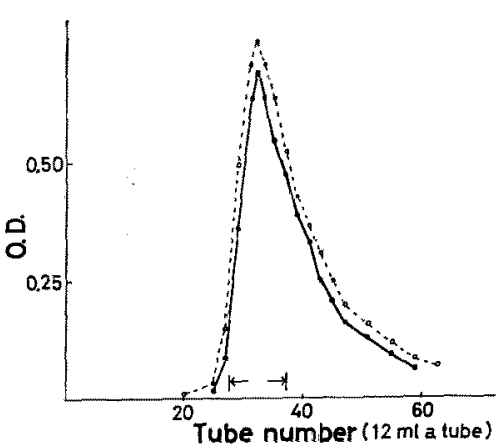

Fig. 1. Gel filtration of PP on Sephadex G-200.

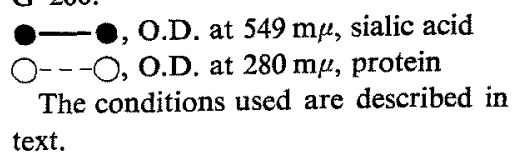
$60 \%$ of saturation with ammonium sulfate, and allowed to stand for $12 \mathrm{hr}$ at $4^{\circ} \mathrm{C}$. The resulting precipitate was purified by gel filtration on Sephadex G-75. Hyaluronidase obtained had an activity ${ }^{3)}$ of $200 \mathrm{TRU} / \mathrm{mg}$ protein.

Hyaluronidase digestion of PP. Five hundred milligrams of PP was dissolved in $50 \mathrm{ml}$ of $0.1 \mathrm{M}$ sodium acetate buffer, $\mathrm{pH} 5.5$, containing $0.45 \mathrm{~g}$ of $\mathrm{NaCl}$. To the solution were added $20 \mathrm{mg}$ of hyaluronidase and $1 \mathrm{ml}$ of toluene, and the mixture was incubated at $37^{\circ} \mathrm{C}$. After $15 \mathrm{hr}, 20 \mathrm{mg}$ of hyaluronidase was again added, and incubation was continued for an additional $20 \mathrm{hr}$.

Pronase digestion of hyaluronidase-degraded PP. To $20 \mathrm{ml}$ of the sialic acid-containing fraction obtained by gel filtration of hyaluronidase-digested PP on Sephadex G-75 (Fig. 2) were added $60 \mathrm{mg}$ of calcium acetate, $10 \mathrm{mg}$ of Pronase-P (proteolytic enzyme from Streptomyces griseus, Kaken Chemical Co., Ltd.), and $1 \mathrm{ml}$ of toluene. The mixture was adjusted to $\mathrm{pH} 8$ with $\mathrm{NaOH}$, and incubated at $40^{\circ} \mathrm{C}$. Similar amounts of Pronase were added at intervals of $20 \mathrm{hr}$ periods. The digestion was continued for a total of $60 \mathrm{hr}$.

Analytical methods. Sialic acid, hexose, uronic acid, and hexosamine were determined as described previously ${ }^{1)}$, except that purification of hydrolyzate with a Dowex 50 column was omitted in hexosamine determination. Sulfate was determined by the method of ANTONOPOULOs ${ }^{2}$. Neutral and amino sugars were identified by gas chromatography according to the following procedure. About $2 \mathrm{mg}$ of each sample was hydrolyzed with $1 \mathrm{ml}$ of $2 \mathrm{~N} \mathrm{HCl}$ in a sealed tube at $100^{\circ} \mathrm{C}$ for $3 \mathrm{hr}$. The hydrolyzate was neutralized with Dowex $1-\times 8\left(\mathrm{CO}_{3}^{--}\right)$, and filtered to remove the resin. The filtrate was passed through a column $(0.7 \times 2.5 \mathrm{~cm})$ of Dowex $50-\times 8\left(200-400\right.$ mesh, $\left.\mathrm{H}^{+}\right)$, and the effluent was evaporated to dryness under reduced pressure. The residue (neutral sugars) was trimethylsilylated $^{4)}$ as follows. One hundred microliters of pyridine, $20 \mu l$ of hexamethyldisilazane, 
and $10 \mu \mathrm{l}$ of trimethylchlorosilane were added successively to the residue. The mixture was gently shaken for $1 \mathrm{~min}$, and allowed to stand at room temperature for $20 \mathrm{~min}$. A 2- $\mu 1$ aliquot was injected into a Shimazu gas chromatograph, Model 4 APF, equipped with a flame ionization detector. A glass column $(0.4 \times 200 \mathrm{~cm})$ packed with $5 \%$ neopentylglycol succinate on Chromosorb W (60-80 mesh) was employed. Amino sugars absorbed on the Dowex 50 column were eluted with $3 \mathrm{ml}$ of $2 \mathrm{~N} \mathrm{HCl}$, and the eluate was evaporated to dryness under reduced pressure. The residue was placed overnight in a vacuum desiccator over phosphorus pentoxide and $\mathrm{KOH}$ pellets, and trimethylsilylated by the method of RAdHAKrishnamurthy et al. ${ }^{5)}$ Accordingly, $100 \mu \mathrm{l}$ of hexamethyldisilazane reagent, prepared by adding $0.2 \mathrm{ml}$ of hexamethyldisilazane to $1 \mathrm{ml}$ of dimethylformamide, was added to the residue. The mixture was heated in boiling water for $2 \mathrm{~min}$, and then cooled to room temperature. A 2- $\mu$ l aliquot was injected into the gas chromatograph. A glass column $(0.4-250 \mathrm{~cm})$ packed with $5 \%$ SE-30 on Shimalite W $(60-80$ mesh) was employed.

\section{Results and Discussion}

After the treatment of purified PP with hyaluronidase, the digestion products were separated by gel filtration on Sephadex G-75. The effluent was analyzed for sialic acid, uronic acid, and protein, and the elution patterns are shown in Fig. 2. PP of cartilage is the protein complex of chondroitin sulfate and keratosulfate, in which these acid mucopolysaccharides seem to be bound to the same protein $^{6-9)}$. Thus, the first peak in the gel filtration of the digest might be expected to contain the material consisting of protein, keratosulfate, and the oligosaccharide remains of chondroitin sulfate. In this peak, all of the sialic acid originally present in PP was found. The second peak was oligosaccharide fragments derived from chondroitin sulfate. No sialic acid was detected in this peak. The sialic acid-containing fraction indicated by arrows was treated with Pronase, and the digest was chromatographed on a column of Sephadex G-50. The effluent was analyzed forsialic acid, hexose, uronic acid, and peptides, and the results are shown in Fig.

3. The heterogeneous peak emerging first was

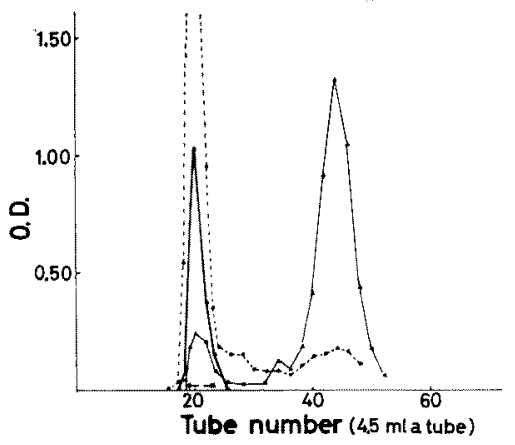

Fig. 2. Gel filtration of hyaluronidase digest of PP on Sephadex G-75.

$$
\begin{aligned}
& \text { acid }, \text { O.D. } \times(1 / 3) \text { at } 549 \mathrm{~m} \mu \text {, sialic } \\
& \text { acid } \triangle, \text { O.D. } \times(1 / 9) \text { at } 530 \mathrm{~m} \mu \text {, uronic } \\
& \text { A } 10 \text {-ml aliquot of the digest (see text) } \\
& \text { was applied to a column }(2.5 \times 65 \mathrm{~cm}) \\
& \text { of Sephadex G-75 equilibrated with } \\
& \text { 0.1 M NaCl. Elution was carried out } \\
& \text { with the same solution. }
\end{aligned}
$$


a glycopeptide fraction; most of it was eluted just past the void volume of the column. All the sialic acid was found in this peak. The elution patterns of sialic acid and hexose were similar, suggesting that these constituents belonged to the same glycopeptide. They also showed that the glycopeptide was heterogeneous in molecular size. The glycopeptide fraction indicated by arrows was fractionated into five fractions by Dowex $1-\times 2$ chromatography (Fig. 4), and these fractions were analyzed for sialic acid, hexose, hexosamine, uronic acid, and sulfate. The analytical data are shown in Table 1. Large amounts of sialic acid were found in all the fractions; particularly in 0.5 and $1.0 \mathrm{M} \mathrm{NaCl}$ fractions, the sialic acid contents amounted to about $19 \%$. Sugar components of each fraction were trimethylsilylated, and then identified by gas chromatography. Figs. 5 and 6 show the gas chromatograms of neutral and amino sugars of the $1.5 \mathrm{M} \mathrm{NaCl}$ fraction. Similar gas chromatograms were also obtained in the case of the other fractions. Major components were galactose and glucosamine.

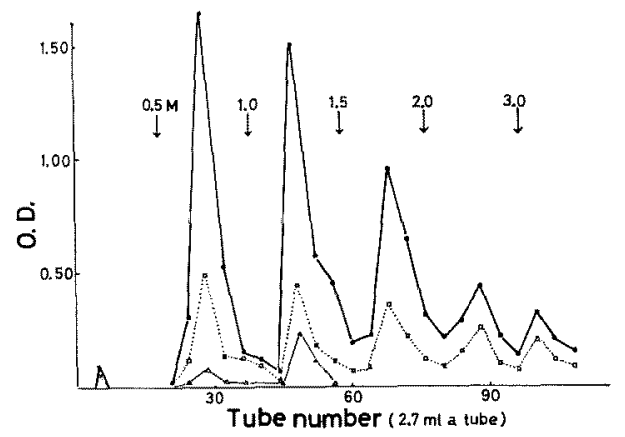

Fig. 4. Dowex $1-\times 2$ chromatography of the sialic acid-containing fraction obtained from Pronase digest of hyaluronidase-degraded PP.

O.D. at $549 \mathrm{~m} \mu$, sialic acid $\triangle-\triangle$, O.D. at $530 \mathrm{~m} \mu$, uronic acid

$\square \cdots \square$, O.D. at $620 \mathrm{~m} \mu$, hexose

The sialic acid-containing glycopeptide fraction indicated by arrows in Fig. 3 was desalted by gel filtration on Sephadex G-25, and applied to a column $(1.2 \times 28 \mathrm{~cm})$ of Dowex $1-\times 2$ (200-400 mesh, $\mathrm{Cl}^{-}$). Elution was carried out stepwise with each of $60-\mathrm{ml}$ volumes of water and solutions containing $\mathrm{NaCl}$ at $0.5,1.0,1.5,2.0$, and $3.0 \mathrm{M}$. Eluants were exchanged at the points indicated by arrows. 
In addition to these, small amounts of galactosamine, mannose, and fucose were also detected. As shown in Table 1, the molar ratios of hexose to hexosamine in all the fractions were nearly 1 to 1 ; most of these sugars were galactose and glucosamine. More-

Table 1. Analyses of fractions obtained by Dowex $1-\times 2$ chromatography.

\begin{tabular}{l|c|c|c|c|c}
\hline \hline Fraction & Sialic acid & Hexosamine & Hexose & Uronic acid & Sulfate \\
\hline $0.5 \mathrm{M} \mathrm{NaCl}$ & 0.47 & 1.00 & 0.91 & 0.04 & 0.30 \\
1.0 & 0.44 & 1.00 & 0.89 & 0.15 & 0.61 \\
1.5 & 0.39 & 1.00 & 0.97 & 0.0 & 0.68 \\
2.0 & 0.31 & 1.00 & 1.13 & 0.0 & 0.89 \\
3.0 & 0.27 & 1.00 & 1.02 & 0.0 & 1.35 \\
\hline
\end{tabular}

Values are expressed as molar ratios to hexosamine.

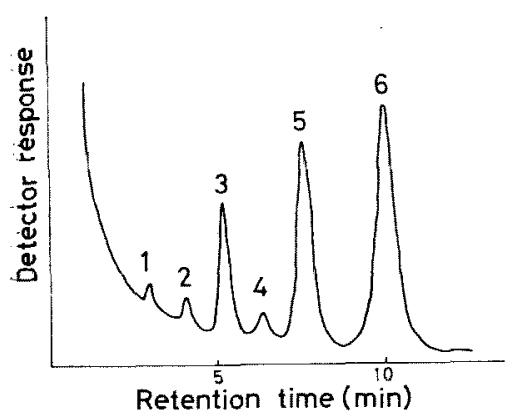

Fig. 5. Gas chromatogram of trimethylsilyl derivatives of neutral sugars of $1.5 \mathrm{M} \mathrm{NaCl}$ fraction.

1,2 , fucose; 3 , mannose; $4,5,6$, galactose

Column temperature, $155^{\circ} \mathrm{C}$; Carrier gas, $\mathrm{N}_{2}$; Flow rate, $50 \mathrm{ml} / \mathrm{min}$

In the conditions used (see text), both fucose and mannose gave two peaks and galactose gave three peaks. Another peak of mannose overlapped the peak 5. The multiplicity of peaks was caused by anomeric isomers which occurred in aqueous equilibrium solutions of sugars.

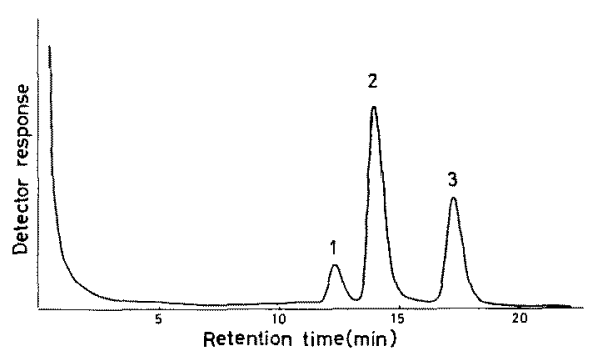

Fig. 6. Gas chromatogram of trimethylsilyl derivatives of amino sugars of $1.5 \mathrm{M} \mathrm{NaCl}$ fraction.

1, galactosamine; 2 , glucosamine + galactosamine; 3 , glucosamine Column temperature, $190^{\circ} \mathrm{C}$

In the conditions used, both glucosamine and galactosamine gave two peaks. The second peak was a glucosamine peak overlapped with a very small galactosamine peak.

over, variable amounts of sulfate were found. From the above evidences, these fractions seem to be a mucopolysaccharide resembling keratosulfate ${ }^{7,10,11)}$ which is composed of galactose and glucosamine in a ratio of about 1 , and has a ratio of sulfate to glucosamine of 1 or greater. This mucopolysaccharide had the following features: (a) it contained a large amount of sialic acid as well as small amounts of galactosamine, mannose, and fucose. (b) most of it was eluted with 0.5-1.5 M NaCl solutions from the Dowex $1-\times 2$ column, while keratosulfate isolated from bovine cornea by MATHEws $e t$ al. ${ }^{11)}$ was eluted from a Dowex $1-\times 2$ column only with $\mathrm{NaCl}$ solutions above a concentration of $2 \mathrm{M}$.

Uronic acid found in the 0.5 and $1.0 \mathrm{M} \mathrm{NaCl}$ fractions appeared to be a component 
of the oligosaccharide remains of chondroitin sulfate, which were left after enzymatic degradation of PP.

Detailed studies on the keratosulfate-like mucopolysaccharide containing a large amount of sialic acid appear necessary for establishment of the structure of PP.

\section{Acknowledgment}

The author wishes to thank Prof. M. Toyomizu for many helpful discussions and suggestions during this work, and he is also grateful to the Fukuoka Branch of Kyokuyo Co., Ltd. for the kind supply of fresh nasal cartilage of whales.

\section{References}

1) H. NAKagawa: This Bull., 37, 192-196 (1971).

2) C. A. Antonopoulos: Acta Chem. Scand., 16, 1521-1522 (1962).

3) S. Tolksdorf: Methods of Biochem. Anal., 1, 439-445 (1954).

4) C. C. Sweeley, R. Bentley, M. Makita, and W. W. Wells: J. Am. Chem. Soc., 85, 2497-2507 (1963).

5) B. Radhakrishnamurthy, E. R. Dalferes, Jr., and G. S. Berenson: Anal. Biochem., 17, 545550 (1966).

6) M. SchuberT: in "Structure and Function of Connective and Skeletal Tissue", 124-131, Butterworth \& Co., Ltd., London (1965).

7) N. Seno, K. Meyer, B. Anderson, and P. Hoffman: J. Biol. Chem., 240, 1005-1010 (1965).

8) P. Hoffman and T. A. MAShBurN, JR.: ibid., 242, 3805-3809 (1967).

9) E. L. Rosenblum and J. A. Cifonelli: Fed. Proc., 26, 282 (1967).

10) J. S. Brimacombe and J. M. Webrer: in "Mucopolysaccharides", 136-138, Elsevier Publishing Co., Amsterdam (1964).

11) M. B. Mathews and J. A. Crfonelli: J. Biol. Chem., 240, 4140-4145 (1965). 